\title{
'Wansevwan', an Improved Pawpaw Cultivar with Mild Flavor and a Tendency for Single Fruit Clusters
}

\author{
R Neal Peterson and Alan R Biggs* \\ Division of Plant and Soil Sciences, West Virginia University, USA
}

Submission: December 08, 2016; Published: January 03, 2017

*Corresponding author: Alan R Biggs, Division of Plant and Soil Sciences, West Virginia University, Kearneysville TFREC, PO Box 609, Kearneysville, WV 25430, Tel: +013048766353; Email: alan.biggs@mail.wvu.edu

\begin{abstract}
'Wansevwan' is a superior pawpaw cultivar with mid to late season ripening, superior fruit quality, many single fruit clusters, few seeds, and high yields relative to wild genotypes. 'Wansevwan' is outstanding for flavor, having the finest mild flavor found in pawpaws to date. 'Wansevwan' possess the minimum overall qualities required for the development of a commercial pawpaw industry. The primary use of this pawpaw cultivar will be for fresh eating as a dessert fruit; secondary use will be in processed products such as ice cream, yogurt, juice, and cosmetics.
\end{abstract}

Keywords: Minor fruit breeding; Asimina triloba; Fruit quality; Improvement

Abbreviations: RHS: Royal Horticultural Society; SFR: Seed to Fruit Ratio

\section{Introduction}

Pawpaw (Asimina triloba L. Dunal) is the largest native edible fruit in North America, indigenous to 26 of the eastern United States, and identified as a species with potential for domestication [1]. Selection of pawpaws from the wild has been practiced for more than a century resulting in availability of numerous non-tested, nonregistered cultivars in the nursery trade. In 2004, this cultivar and two others were briefly described [2]. In 2011, a cultivar named 'KSU Atwood' was registered [3]. Scientific attention towards improving the fruit, its culture, and post-harvest handling had been neglected until 1992, with much work done subsequently at Kentucky State University [4,5]. The present article is the first to provide details of the tree and fruit characteristics 'Wansevwan.'

\section{Materials and Methods}

'Wansevwan' is the result of a selection program begun in 1982 entailing 1500 seedling trees originating as openpollinated seed from antique collections of pawpaw dating back to the early 20th century [6]. Source plants were the surviving remnants of five historic collections of pawpaw that were the work of the most prominent pawpaw collectors and breeders of the time, and whose named material was no longer propagated or otherwise available. In 1982, open-pollinated seed was collected from these remnants and included with open-pollinated seed from named cultivars, which became the source material for future breeding and selection efforts.

In 1983, seed were germinated and the following spring 808 accessions were planted at the University of Maryland experiment station, the Wye Research \& Education Center, Queenstown, Md. Plants were pruned, fertilized, and kept weedfree, and data were collected on growth rates, flowering, fruit set, yields, cluster size, fruit size and fruit quality, including data from taste panels.

In 1991, four years of data were analyzed and eleven trees were identified as superior and were segregated for further study. Nine of these 11 selections were assigned to regional variety trials at various locations in the United States. After nine additional years of observation, the original nine selections were narrowed to three that were consistently of the highest quality. One of the three was accession number PPF 1-7-1, and is the cultivar described herein. 'Wansevwan' originated as an open-pollinated seedling from the variety 'Overleese,' which is a nonregistered, non-patented cultivar originating circa 1950 near Rushville, Indiana, and which is generally regarded as the standard pawpaw variety among pawpaw growers. 
In 1994, top-working research was initiated at the Wye orchard with the 11 advanced selections, plus other alreadynamed cultivars. Top-working was accomplished using barkinlay grafting and chip-budding. Grafting of 'Wansevwan' was easily accomplished by established methods, and gave a high percentage of takes, approximately $75 \%$. The rootstock for these grafts was mature seedling pawpaw trees growing in the orchard, and was a portion of the original accessions from 1983, described previously. Eight grafted trees of 'Wansevwan' have been bearing fruit since 1996 and demonstrate that asexual reproduction of this new and distinct cultivar preserves the desirable characteristics of the variety and establishes and stably transmits those characteristics through successive propagation.

\section{Results and Discussion}

The variety 'Wansevwan' was discovered as the result of a breeding and evaluation project conducted between 1982 and 2000. In 1982 open-pollinated seeds were collected from the surviving remnants of historic pawpaw collections dating to the early 20th century, as well as open-pollinated seed from certain named cultivars, including 'Overleese'. One seedling tree bearing the accession number PPF 1-7-1 is the new cultivar named 'Wansevwan', having originated as an open-pollinated seedling from the variety 'Overleese', a nonregistered cultivar originating near Rushville, Indiana, circa 1950, and which is regarded as a standard pawpaw cultivar [1,6]. 'Wansevwan' exceeds its maternal parent in most regards, viz., size, yield, flavor, and few seeds.

Trees of 'Wansevwan' reach a mature height of 5 to $8 \mathrm{~m}$. Tree form is pyramidal in youth becoming rounded with age. This cultivar responds well to pruning, forming a broadly spreading tree of globular shape with wide crotch angles. Pruning has an invigorating effect that stimulates growth and fruit bearing. Corrective pruning is minimal. It is easy to graft by most conventional methods; percent success is about $75 \%$.

The flower is slightly smaller than average (37 mm mean), more tightly closed than typical in the female stage, and more widely flaring than typical in the male stage. Average ratio of leaf width to length is 0.435 . Mean petiole length is $14.2 \mathrm{~mm}$ [7].

Insects and pathogens are the same as for the wild-type species, and includes three lepidopteran larvae, Talponia plummeriana, the pawpaw peduncle borer, Protographium marcellus, the zebra swallowtail butterfly, and Omphalocera munroei, the pawpaw webworm. T. plummeriana is capable of inflicting economic damage in exceptional seasons, destroying the majority of flowers. A fungal complex of Phyllosticta asiminae, Mycocentrospora asiminae, and Rhopaloconidium asiminae causes leaf spot and fruit spot. Fruit spot is unsightly and predisposes fruit to cracking.

Bloom time is approximately mid April to mid May in the mid-Atlantic United States. Blooms are susceptible to late spring freezes; however, it is notable that the dormant flower buds are winter hardy to $-30{ }^{\circ} \mathrm{C}$. 'Wansevwan' is weakly self-compatible, and requires other cultivars for good fruit set.

Well-pollinated fruit are large, 260 gm mean and may exceed $450 \mathrm{gm}$. Shape is normally ovoid-ovate with dorsal side slightly flattened. Large well-formed fruit have proportions that tend towards 100:70:65 (length: width: depth) (Figure 1). The point of peduncle attachment is greatly offset from the long axis of the fruit, on the dorsal side. A suture is often visible on the ventral side. Fruit set is low, usually $<20 \%$. Yields are approximately $13.5 \mathrm{~kg}$ of fruit per mature tree- high relative to the species but low when compared to other tree fruits such as apple.

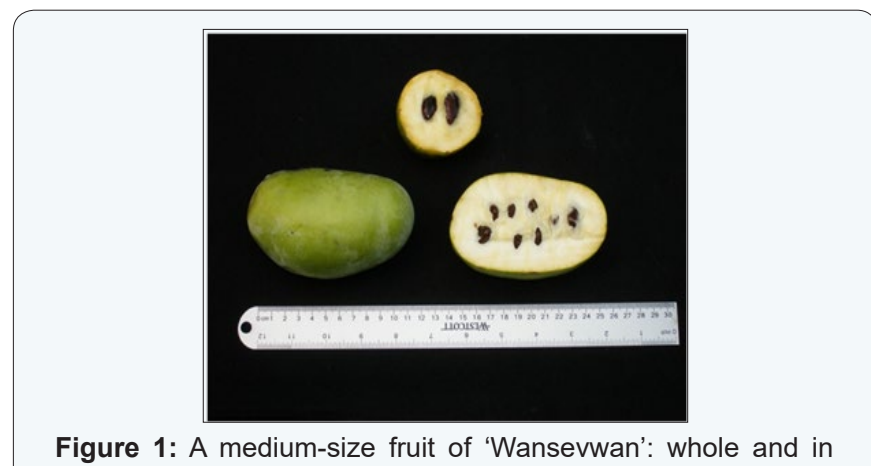

transverse and longitudinal sections.

Skin of under-ripe fruit is pale green and glaucous (RHS Yellow-Green 147D); of ripe fruit is pale yellowish green and glaucous (RHS Yellow-Green 145A). Fruit does not exhibit a reliable color break as a visual guide for picking. After fruit passes its climacteric peak, brown blotches appear that spread to cover the entire skin surface (typical for the species).

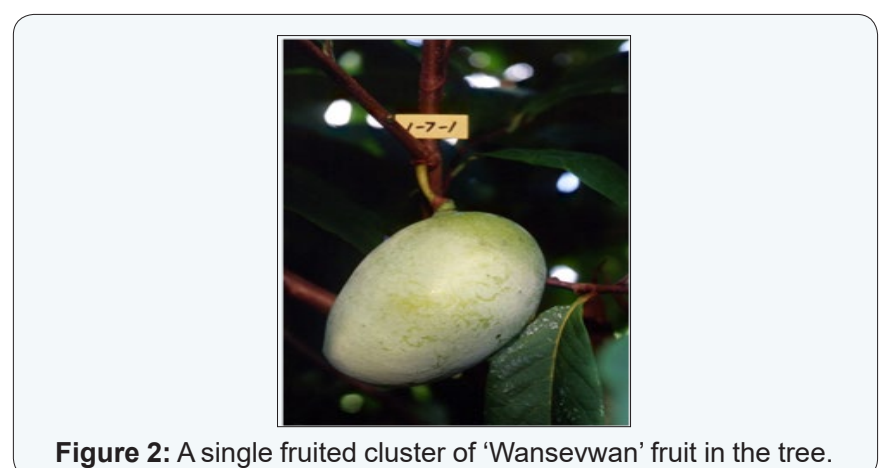

Figure 2: A single fruited cluster of 'Wansevwan' fruit in the tree.

Fruit are borne in clusters of 1,2 or 3, and as many as 5 . Single-fruited clusters are common (very unusual for the species), a trait that facilitates harvest (Figure 2). The fruit skin is thin to medium-thin. Composition is fleshy; the average quantity of pulp per seed is $26.1 \mathrm{gm}$; and the seed: fruit ratio by weight (SFR) is only $5.4 \%$. Wild trees usually have SFR in the range 15 to $25 \%$.

Aroma of the fruit before and after cutting is pleasant, neither too faint nor too pronounced. Flavor is excellent-very sweet, with soluble solids at $18 \%$, mild, non-bitter, and nonastringent, and with a pleasant aftertaste. Flesh color is creamy 
yellow and uniform throughout (RHS Yellow 12C). The pungent 'asiminous' component that is uniquely pawpaw and that many people find objectionable is noticeably weak. The flesh is firmer than average, very custardy and melting, with a pleasant mouthfeel and no detectable fiber or grit.

The ripening period at Queenstown, MD, (latitude 3859' N) has been mid to late season, September 10 to 24, more or less, depending on the heating degree-day accumulation in the preceding months. Keeping quality of ripe fruit is short at ambient temperature $\left(24^{\circ} \mathrm{C}\right)$ roughly three days (typical for the species). Keeping quality in cold storage $\left(2^{\circ} \mathrm{C}\right)$ is moderate at three weeks when picked two-days under-ripe.

\section{Conclusion}

Cultivar 'Wansevwan' is sold commercially under the trademark name Shenandoah ${ }^{\mathrm{TM}}$ [7]. It is available from the senior author and from Kentucky State University for scientific research. To date, our program has produced 12 advanced selections and five additional named cultivars, including: 'Allegheny', 'Potomac', 'Rappahannock', 'Susquehanna' and 'Wabash'. These 18 cultivars are part of regional variety trials in the eastern United States, along with the continuing breeding program conducted at West Virginia University. Among these cultivars, several are superior in terms of fruit quality and yields, consistently ranking at or near the top in taste tests and physical parameters (size, fleshiness, texture, and few seeds) [8].

\section{Acknowledgments}

Appreciation is extended to David Leach and Tim Winfield of the West Virginia University Tree Fruit Research and Education
Center, and Harry Swartz, Christopher Walsh, and Michael Newell of the University of Maryland, for advice and technical assistance. This is publication number Scientific Article No. 3294 of the West Virginia Agricultural Experiment Station. Funding for this work was provided in part by the West Virginia Agricultural Experiment Station. Mention of a trademark, proprietary product, or vendor does not constitute a guarantee or warranty of the product by West Virginia University and does not imply its approval to the exclusion of other products or vendors that also may be suitable.

\section{Conflict of Interest}

The authors declare no conflict of interest. The funding sponsors had no role in the design of the study; in the collection, analyses, or interpretation of data; in the writing of the manuscript, and in the decision to publish the results.

\section{References}

1. Peterson RN (1991) Pawpaw (Asimina). In: J NMoore and J R Ballington (eds.), Genetic resources of temperate fruit and nut crops, 2(20).

2. Okie WR (2004) Register of New Fruit and Nut Varieties List 42 . Hort Science 39(6): 1509-1523.

3. Pomper KW CrabtreeSB Lowe JD (2011) The North American Pawpaw Variety: 'KSU-Atwood'⿳⺈'. J Amer Pomol Soc 65: 218-221.

4. Pomper KW Layne DR (2005) The North American pawpaw: botany and horticulture. Hort Rev 31: 351-384.

5. Pomper KW, Crabtree SB, Layne DR, Peterson RN, Masabni J, et al. (2008) The Kentucky Pawpaw Regional Variety Trial. J Amer Pomol Soc 62(2): 58-69.

6. Peterson RN (2003) Pawpaw variety development: a history and future prospects. Hort Technology 13(3): 449-454.

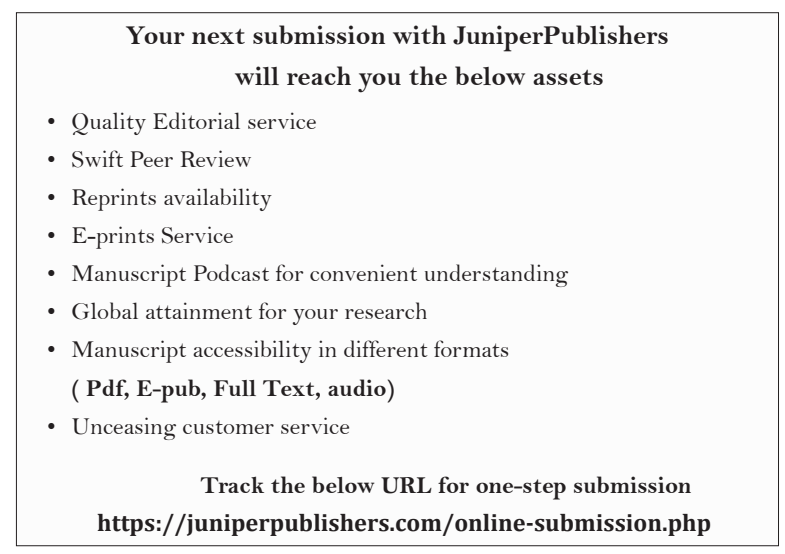

